\title{
Slit3 inhibits activator protein 1-mediated migration of malignant melanoma cells
}

\author{
ALEXANDRA E. DENK* ${ }^{*}$ SIMONE BRAIG* ${ }^{*}$, THOMAS SCHUBERT and ANJA K. BOSSERHOFF \\ Institute of Pathology, University of Regensburg, Regensburg, Germany
}

Received May 5, 2011; Accepted June 11, 2011

DOI: $10.3892 / \mathrm{ijmm} .2011 .742$

\begin{abstract}
The repellent factor family of Slit molecules has been described to have repulsive function in the developing nervous system on growing axons expressing the Robo receptors. Alterations of the Slit/Robo system have been observed in various pathological conditions and in cancer. However, until today no detailed studies on Slit function on melanoma migration are available. Therefore, we analysed the mRNA expression in melanoma cells and found induction of Robo3 expression compared to normal melanocytes. Functional assays performed with melanoma cells revealed that treatment with Slit3 led to strong inhibition of migration. Interestingly, we observed down-regulation of AP-1 activity and target gene expression after Slit3 treatment contributing to the negative regulation of migration. Taken together, our data showed that Slit3 reduces the migratory activity of melanoma cells, potentially by repulsion of the cells in analogy to the neuronal system. Further studies will be necessary to prove Slit activity in vivo, but due to its function, Slit3 activity may be helpful in the treatment of melanoma.
\end{abstract}

\section{Introduction}

Cutaneous malignant melanoma is one of the most common types of cancer worldwide with rising incidence rates $(1,2)$. Despite this rising trend current therapeutic options are very limited, especially after the development of distant metastases $(3,4)$.

Our aim in this study was to find new ways for the treatment of malignant melanoma that have not yet been utilised. The repellent-factor family of Slits and their receptors, the

Correspondence to: Professor Anja Katrin Bosserhoff, Institute of Pathology, University of Regensburg, Franz-Josef-Strauss-Allee 11, D-93053 Regensburg, Germany

E-mail: anja.bosserhoff@klinik.uni-regensburg.de

*Contributed equally

Abbreviations: Robo, roundabout; rmSlit3, recombinant mouse Slit3

Key words: repellent factor, Slit, Robo, migration, proliferation, malignant melanoma roundabouts (Robos) are best known for mediating axon guidance through attraction or repulsion of growth cones [reviewed in $(5,6)]$ but also play a role in regulating cell-cell- and cellmatrix-interactions of migrating cells during embryonic development (7). In addition, their expression is known to correlate with tumour angiogenesis (8-10).

In the last years, it has been shown that deregulation of Robo and Slit can have crucial consequences for multiple cancers. Slit2 for example can suppress tumour growth in breast cancer (11) and recent findings show that Slit and Robo expression is deregulated during hepatocarcinogenesis (12) and in cervical cancer (13). It has also been described, that the Slit/Robo system can inhibit the growth factor-mediated cell motility and morphogenesis of different cancer cell lines (14).

Therefore, we began to investigate a potential role of the Slits and Robos in different malignant melanoma cell lines, starting with expression analyses. We then focused on Slit3 as a potential therapeutic agent in malignant melanoma and showed that Slit3 can inhibit migration of malignant melanoma cells in vitro.

\section{Materials and methods}

Cell culture. The melanoma cell lines Mel Im, Mel Ei, Mel Juso, HMB2, SK Mel3 and SK Mel28 were used as previously described (15). The melanoma cell line A375 was used as described in Bundscherer et al (16). Briefly, cells were maintained in DMEM supplemented with penicillin $(400 \mathrm{U} / \mathrm{ml})$, streptomycin $(50 \mu \mathrm{g} / \mathrm{ml})$, L-glutamine $(300 \mu \mathrm{g} / \mathrm{ml})$ and $10 \%$ fetal calf serum (FCS) (Sigma, Deisenhofen, Germany) and split at a 1:5 ratio every 3 days. Human primary melanocytes derived from normal skin (NHEM) were cultivated in melanocyte medium MGM-3 (Gibco, Eggenstein, Germany) under a humidified atmosphere of $5 \% \mathrm{CO}_{2}$ at $37^{\circ} \mathrm{C}$. The purity of the melanocytes was proven by confirming the expression of melanocytic markers like tyrosinase, TRP-1 and E-cadherin and a lack of keratinocytic markers like cytokeratin 5, -10 or -14 and KGF receptor. Cells were used between passages 3 to 6 and detached for subcultivation or assay with $0.05 \%$ trypsin, $0.02 \%$ EDTA in PBS. Recombinant mouse Slit3 (rmSlit3) (R\&D Systems) was used in all cell culture experiments at a concentration of $0.1 \mu \mathrm{g} / \mathrm{ml}$.

RNA isolation and reverse transcription. Total cellular RNA was isolated from cultured cells using the RNeasy kit (Qiagen, 
Hilden, Germany) and cDNAs were generated by reverse transcriptase reaction as previously described (15).

Quantitative real-time PCR (RT-PCR). Quantitative RT-PCR was performed on a LightCycler (Roche, Mannheim, Germany) using $10 \mu \mathrm{l}$ SYBR Mix (Takara, Shiga, Japan), $0.5 \mu \mathrm{l}(20 \mu \mathrm{M})$ of forward and reverse primers and $1 \mu \mathrm{l}$ cDNA template in a total of $20 \mu \mathrm{l}$. cDNA fragments were amplified according to the following PCR program: $30 \mathrm{sec} 95^{\circ} \mathrm{C}$ (initial denaturation); $20^{\circ} \mathrm{C} / \mathrm{sec}$ temperature transition rate up to $95^{\circ} \mathrm{C}$ for $5 \mathrm{sec}$, $10 \sec 55^{\circ} \mathrm{C}, 15 \sec 72^{\circ} \mathrm{C}$ (for Robo1, Robo2, Robo3) or $95^{\circ} \mathrm{C}$ for $3 \mathrm{sec}, 10 \mathrm{sec} 58^{\circ} \mathrm{C}, 8 \sec 72^{\circ} \mathrm{C}$ (for MMP2 and MMP14) and $10 \mathrm{sec} 82^{\circ} \mathrm{C}$ acquisition mode single, repeated for 40 times (amplification). The annealing temperature was optimized for each primer set and the PCR reaction was evaluated by melting curve analysis following the manufacturer's instructions and checked by electrophoresis. $\beta$-actin was amplified to ensure cDNA integrity and to normalize expression. Each quantitative PCR was performed at least in duplicate for 2 sets of RNA preparations. Primer sequences are available on request.

FACS analysis. Cells $\left(2 \times 10^{6}\right)$ were fixed for $10 \mathrm{~min}$ in $100 \%$ methanol, washed twice in PBS, permeabilized in $0.1 \%$ Tween/ PBS and again washed twice in PBS. Cells were then incubated for $1 \mathrm{~h}$ with anti-Robo3 primary antibody (1:50; Everest Biotech, Oxfordshire, UK) in $1 \%$ BSA/PBS. After three times washing with PBS, cells were incubated for 30 min with Cy5-conjugated anti-goat antibody (1:100; Jackson ImmunoResearch, Suffolk, $\mathrm{UK}$ ) in $1 \% \mathrm{BSA} / \mathrm{PBS}$ and washed thrice in PBS. Finally, cells were resuspended in $300 \mu \mathrm{l} \mathrm{PBS}$ and measured with the BD FACSCanto II (BD Biosciences, Franklin Lakes, USA) and BD FACSDiva software. Data were afterwards analysed with the WinMDI software (version 2.9).

Cloning and expression of Robo2-N-terminal region (Robo2N). Human Robo2 from amino acids 1 to 841 was amplified by PCR (Robo2 forward: 5'-gac gaa ttc aat gag tct get gat gtt tac ac; Robo2 reverse: 5'-gac gaa ttc taa atg aca act tca ttg cgt ctc c) using Phusion Polymerase (NEB, Frankfurt am. Main, Germany) and subsequently cloned into a pcDNA3 vector (Invitrogen, Karlsruhe, Germany) via EcoRI restriction sites.

Mel Im cells were transfected via Lipofectamine Plus (Invitrogen) with Robo2N expressing construct and expression was confirmed by quantitative RT-PCR. Cells were used in migration assays $24 \mathrm{~h}$ after transfection.

Migration assay (Boyden Chamber). The migration assay was performed using Boyden Chambers containing polycarbonate filters with $8 \mu \mathrm{m}$ pore size (Costar, Bodenheim, Germany), as previously described (17). Briefly, filters were coated with gelatine. The lower compartment was filled with fibroblastconditioned medium, used as a chemoattractant. Melanoma cells were harvested with trypsin incubation for $2 \mathrm{~min}$, resuspended in DMEM without FCS at a density of $3 \times 10^{4}$ cells $/ \mathrm{ml}$ and injected in the upper compartment of the chamber on the filter. After incubation at $37^{\circ} \mathrm{C}$ for $4 \mathrm{~h}$, all cells attached to the upper surface of the membrane were removed. Cells adhering to the lower surface were fixed, stained and counted. rmSlit3 (R\&D Systems) was used at a concentration of $0.1 \mu \mathrm{g} / \mathrm{ml}$ and
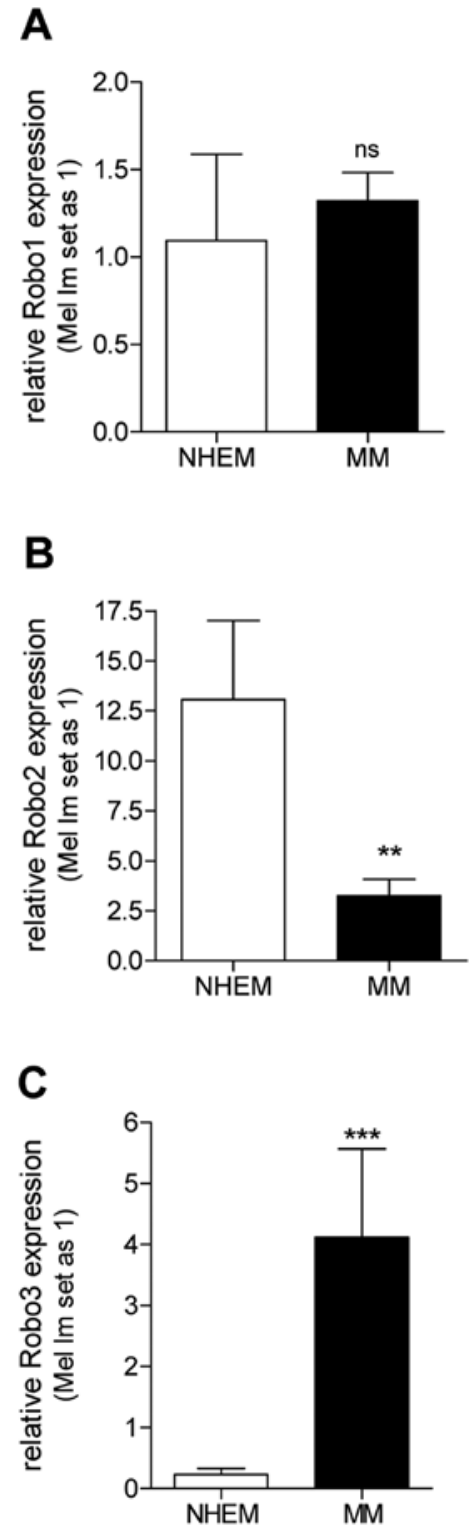

Figure 1. Robo expression in malignant melanoma cells and NHEM. Robo1 (A), Robo2 (B) and Robo3 (C) mRNA was quantified in malignant melanoma cells (7 cell lines), pooled and compared to melanocytes (NHEM; 3 different donors) by qRT-PCR (melanoma cell line Mel Im was set as 1). Robo1 expression was unchanged. Robo 2 expression was dramatically reduced in all melanoma cells compared to melanocytes, whereas Robo3 expression was significantly increased $\left({ }^{* *} \mathrm{P}<0.01 ;{ }^{* * *} \mathrm{P}<0.001\right)$. ns, not significant.

added to the cells in the upper chamber of the system. All experiments were repeated at least three times.

3D-spheroid migration. Spheroids of B16 DC (double transfected with FITC histone and TRITC actin marker) cells were designed after the hanging drop method (18). After $72 \mathrm{~h}$, spheroids were harvested and embedded in collagen matrix \pm rmSlit3 $(100 \mathrm{ng} / \mathrm{ml})$ and covered with DMEM medium mixed with fibroblast-conditioned medium plus FCS $(1: 1) \pm \mathrm{rmSlit} 3(100 \mathrm{ng} / \mathrm{ml})$ which was changed at $24 \mathrm{~h}$. Migration was analyzed after 24, 48, 72 and $96 \mathrm{~h}$ with the Axiovert $200 \mathrm{M}$ and the AxioVision Software 4.5.0.0. For quantification of migration, the area of migrated cells after $72 \mathrm{~h}$ was measured with ImageJ Software $1.41 \mathrm{o}$ and compared 
A
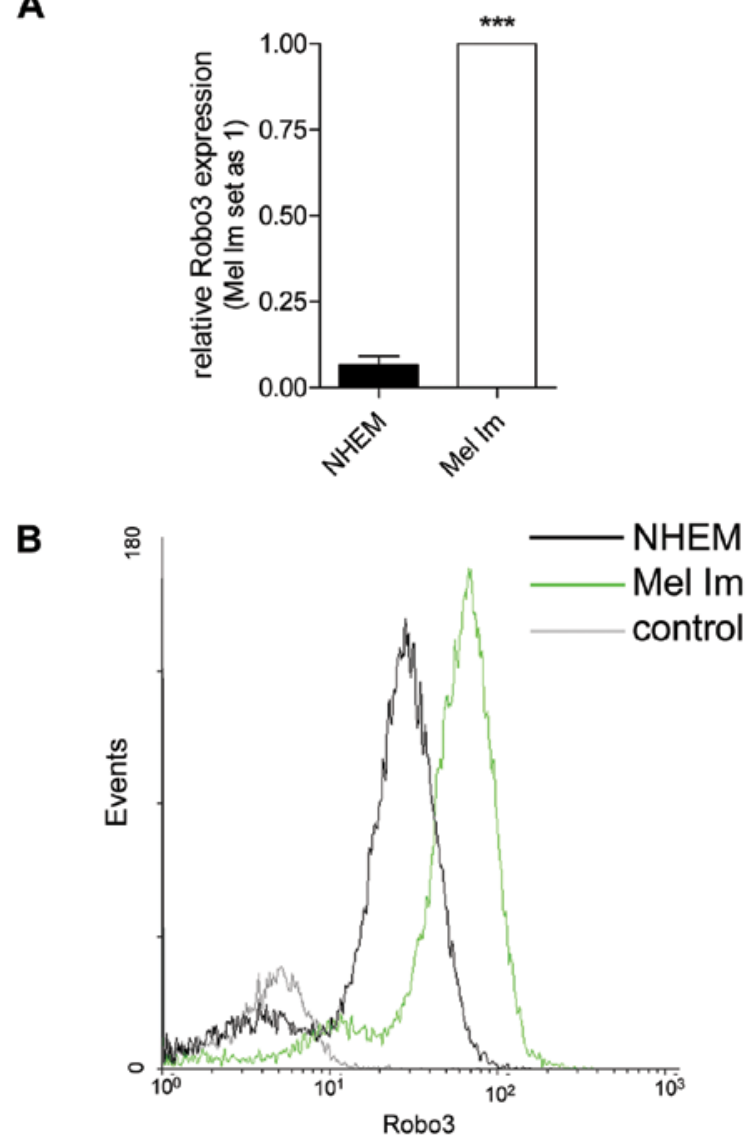

Figure 2. Comparison of Robo3 expression in Mel Im and NHEM. (A) Robo3 mRNA expression in the melanoma cell line Mel Im was quantified via qRT-PCR and compared to melanocytes (NHEM). Significant induction of Robo3 could be detected in the melanoma cell line Mel Im $\left({ }^{* * *} \mathrm{P}<0.001\right)$. (B) Robo3 protein expression was measured via fluorescent activated cell scanning (FACS) in Mel Im cells and compared to NHEM. Higher Robo3 protein levels could be detected in the melanoma cells compared to NHEM.

to the spheroid area, followed by comparison of rmSlit3treated cells and untreated control (set as 100\%).

AP-1 luciferase assay. Mel Im cells (0.2x10\%/well of a 6-well plate) were transfected via the Lipofectamine plus method with $0.5 \mu \mathrm{g}$ plasmid DNA of pGL2-basic or AP-1 luciferase reporter vector. The cells were lysed $24 \mathrm{~h}$ after transfection and luciferase activity in the lysate was quantified (Promega, Mannheim, Germany). Transfection efficiency was normalized according to renilla luciferase activity by co-transfection of $0.1 \mu \mathrm{g}$ of the plasmid pRL-TK (Promega). Transfections were repeated at least four times.

Statistical analysis. Calculations were performed using the GraphPad Prism software (GraphPad software, Inc., San Diego, USA). All results are expressed as mean \pm SD (range) or in $\%$. Error bars represent standard deviation. Comparison between groups was made using the Student's paired t-test (two-tailed).

\section{Results}

Robo expression in malignant melanoma cell lines compared to NHEM. Robo receptor mRNA expression was analysed in seven malignant melanoma cell lines compared to normal human

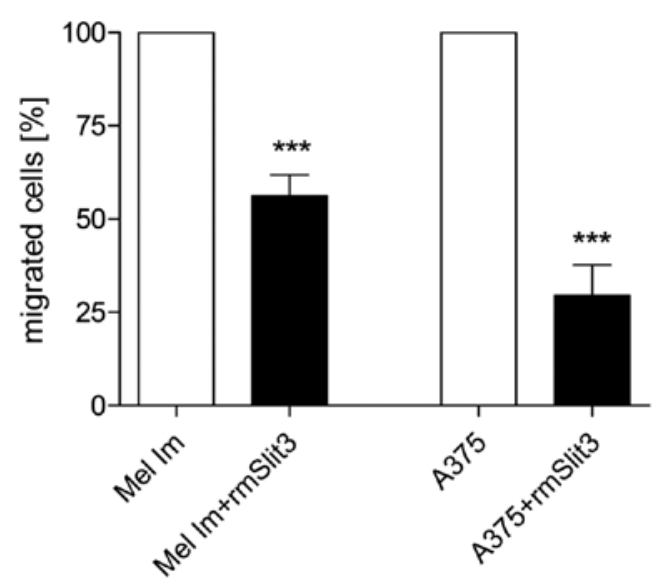

Figure 3. Slit3 effect on migration of malignant melanoma cells in the Boyden Chamber Assay. Mel Im (n=8) and A375 (n=5) cells were tested in the Boyden Chamber assay. Migration was significantly reduced in cells treated with $100 \mathrm{ng} / \mathrm{ml}$ recombinant mouse Slit3 (rmSlit3; $\left.{ }^{* * *} \mathrm{P}<0.001\right)$.

epidermal melanocytes (NHEM) of three different donors by qRT-PCR (Fig. 1). Robol was not differentially expressed (Fig. 1A), whereas Robo2 expression was significantly reduced (Fig. 1B), and Robo3 expression was significantly increased in the melanoma cell lines compared to NHEM (Fig. 1C).

Robo3 protein expression was measured by fluorescent activated cell sorting/scanning (FACS) analysis (Fig. 2B). Compared to the low Robo3 protein-expressing NHEM, a higher Robo3 expression was confirmed in the melanoma cell line Mel Im paralleling the expression at the mRNA level as determined by RT-PCR (Fig. 2A).

Slit3 inhibits migration of melanoma cells Mel Im and A375. The repellent factor family Slit has been described to control neuronal migration (19). We, therefore, aimed to analyse the effect of Slit on melanoma cell migration, since melanoma cells are essentially of neural crest origin. Gain of migratory activity plays a critical role in spreading of melanoma cells during metastasis. Mel Im and A375 (both cell lines derived from melanoma metastases) were treated with rmSlit3 in Boyden Chamber migration assays (Fig. 3). Migration was significantly reduced in both cell lines after Slit3 treatment compared to untreated controls. Proliferation of the melanoma cell lines Mel Im, A375, Mel Ei and Mel Juso was not influenced by Slit3 (data not shown).

Slit3 inhibits migration of B16 mouse melanoma cells in $3 D$. We used B16 cells that were stably transfected with FITC histone marker to illustrate migration of the cells out of a threedimensional (3D) spheroid into a collagen matrix (Fig. 4). This highly reproducible method has the great advantage of abolishing surface interactions (18) and allowed us to study the long term effects of Slit3 on migration. The spheroids treated with rmSlit 3 showed a significant reduction of migration to about $50 \%$ compared to untreated control spheroids.

Robo2N neutralises Slit3-mediated inhibition of migration of melanoma cells. To confirm that inhibition of melanoma cell migration is due to direct Slit effects, we transfected an 
A
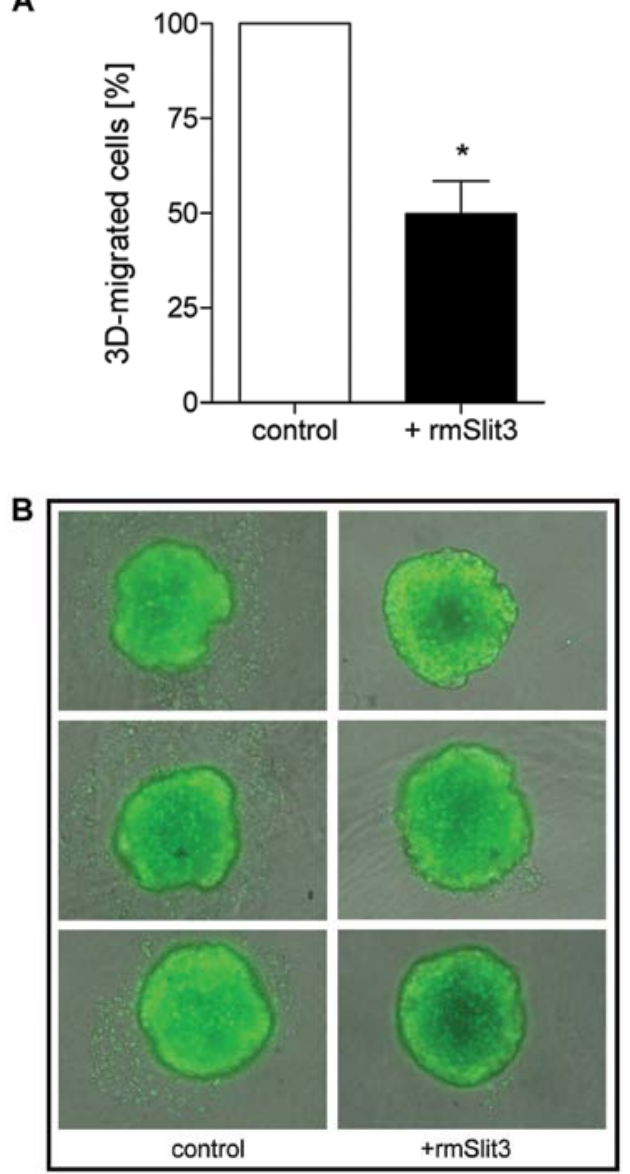

Figure 4. Spheroid migration of B16 melanoma cells. (A) Cells of spheroids treated with rmSlit 3 showed significantly reduced migration compared to the untreated spheroid control ("P<0.05). (B) Representative pictures of three rmSlit3 treated and control spheroids with FITC-labelled histone marker of B16 DC cells.

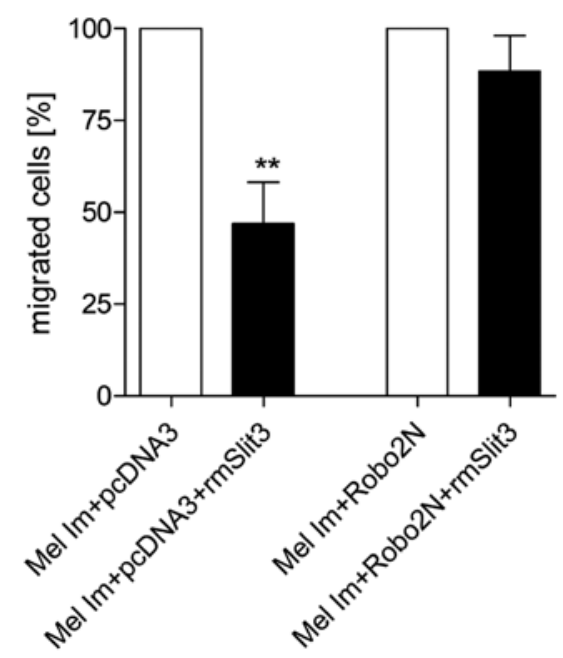

Figure 5. Boyden Chamber migration assay of melanoma cells expressing Robo2N. Mel Im cells were transiently transfected with Robo2N (expression was examined by qRT-PCR; data not shown). The inhibitory effect of rmSlit3 on migration was neutralized in Robo2 $\mathrm{N}$ expressing cells.

expression construct for the N-terminal, extracellular domain of Robo2 (Robo2N) into Mel Im cells (re-expression was controlled by qRT-PCR; data not shown). This soluble receptor

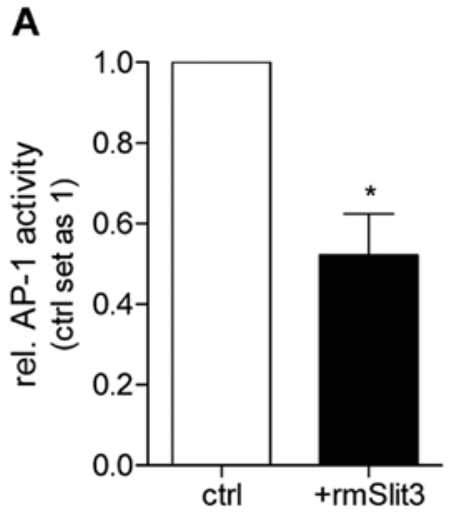

B

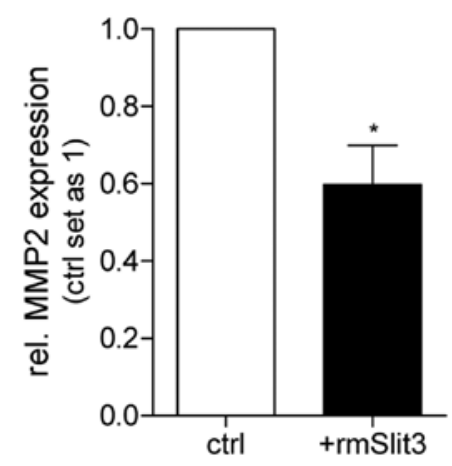

C

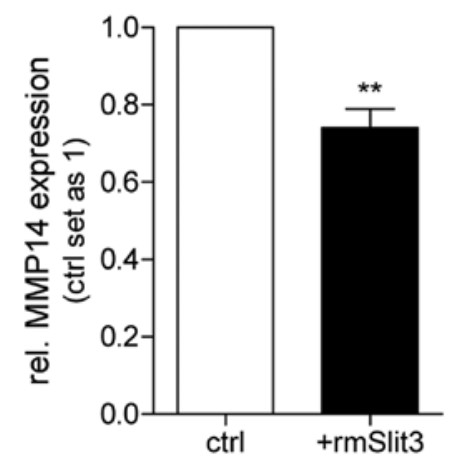

Figure 6. Modulation of AP-1 activity and target gene expression. (A) Mel Im cells treated with rmSlit 3 for $24 \mathrm{~h}$ showed significantly decreased AP-1 activity compared to the untreated control ( $\mathrm{P}<0.05)$. (B) MMP2 expression significantly decreased in rmSlit3-treated Mel Im cells after $24 \mathrm{~h}$ compared to the untreated control ( $\mathrm{P}<0.05$ ). (C) MMP14 expression significantly decreased in rmSlit3-treated Mel Im cells after $24 \mathrm{~h}$ compared to the untreated control $\left({ }^{* *} \mathrm{P}<0.01\right)$.

for the ligand Slit3 was fully capable of neutralising the Slit3mediated inhibition of migration (Fig. 5).

Slit3 modulates AP-1 activity. To elucidate the signalling pathways regulated by Slit/Robo interaction we determined the effect of Slit treatment on strongly activated pathways in melanoma. After treatment with rmSlit 3 for $24 \mathrm{~h}$, activity of AP-1 was significantly reduced to about $50 \%$ compared to untreated control (Fig. 6A), whereas LEF/TCF and NFкB activity were not influenced by rmSlit3 (data not shown).

To analyze, whether Slit3 treatment also affects AP-1 target genes, we determined the expression of MMP2 and MMP14 mRNA via qRT-PCR. Expression of both, MMP2 
and MMP14, were significantly reduced after $24 \mathrm{~h}$ of rmSlit3 treatment (Fig. 6B and C).

\section{Discussion}

The repellent factor family Slit and Robo have been primarily described in axon guidance of neurons and have been extensively reviewed $(5,6,19)$. Recent data suggest that deregulation of the Robo/Slit system can lead to tumour development $(11,12,14,20)$ and influence cell guidance of tumour cells $(21)$.

We revealed a significant loss of Robo2 in melanoma cells compared to normal melanocytes. A recently published study revealed regulation of Robo2 by miR-218 (22). This miRNA is strongly induced in melanoma (23) suggesting that suppression of Robo2 expression could be regulated via miR-218. In addition, strong induction of Robo3 was observed in melanoma cells at the mRNA and protein level suggesting a regulation on the transcriptional level. We recently could link strong Robo3 expression to aggressive, invasive behaviour in synovial fibroblasts derived from patients with rheumatoid arthritis (24), although the molecular mechanisms are still unclear. Potentially, a similar correlation of increased Robo3 expression and aggressiveness and invasive potential may be found in melanoma cells.

It has already been shown that Slit2 can attract vascular endothelial cells via Robol and therefore, promote tumour growth of malignant melanoma cells (8). On the other hand, the nerve repellent factors Slit and Robo may be able to directly regulate melanoma cell migration during the process of tumour dissemination similarly to chemokine attraction (25). In our study, the treatment of melanoma cell lines with Slit3 could strongly reduce the migratory activity of melanoma cells both in the Boyden Chamber and in spheroid migration assays, whereas proliferation of melanoma cells was not affected. This inhibitory effect of Slit3 could be neutralized after expression of the soluble, extracellular Robo2 protein (Robo2N), confirming a direct effect of Slit3. Other studies could show effects of Slit on the migratory potential of non- melanoma cancer cells such as glioma, hepatocellular carcinoma or breast cancer (26-28). A recent study of Yuasa-Kawada et al (29) could define the mechanism in more detail and revealed that the deubiquitinating enzyme USP33 is a mediator of the Slit/Robo signaling. Expression of USP33 is strongly induced in melanoma cells compared to melanocytes (data not shown) suggesting that this modulator of Slit activity could also be of importance in melanoma.

Interestingly, signalling induced by Slit is not via modulation of the $\beta$-catenin/LEF/TCF activity in melanoma cells as suggested by Rhee et al for other cell types (30). We determined a strong inhibitory effect of Slit3 on AP-1 signalling resulting in reduced expression of AP-1 target genes. Until now regulation of this signalling pathway by Slit/Robo has not been reported. We recently described that modulation of the cytoskeleton can influence AP-1 activity by stabilising the c-Jun protein $(31,32)$. Robo/Slit signalling is known to influence actin polymerisation (33) and could influence AP-1 activity via the newly determined pathway.

Taken together, this is the first study where the repellent factor molecule Slit was analysed for further application for the therapy of cutaneous malignant melanoma.

\section{Acknowledgements}

The B16 cells were a kind gift of Mr. Peter Friedl, Nijmegen Center for Molecular Life Sciences (Nijmegen, The Netherlands). We are indebted to Mrs. Simone Kaufmann for excellent technical assistance. The study was supported by a grant from the Wilhelm Sander Foundation.

\section{References}

1. Leiter U and Garbe C: Epidemiology of melanoma and nonmelanoma skin cancer - the role of sunlight. Adv Exp Med Biol 624: 89-103, 2008.

2. Garbe $C$ and Leiter U: Melanoma epidemiology and trends. Clin Dermatol 27: 3-9, 2009.

3. Thirlwell C and Nathan P: Melanoma - part 2: management. BMJ 337: a2488, 2008.

4. Polak ME, Borthwick NJ, Jager MJ and Cree IA: Melanoma vaccines: the problems of local immunosuppression. Hum Immunol 70: 331-339, 2009.

5. Dickson BJ and Gilestro GF: Regulation of commissural axon pathfinding by Slit and its Robo receptors. Annu Rev Cell Dev Biol 22: 651-675, 2006.

6. Rajagopalan S, Nicolas E, Vivancos V, Berger J and Dickson BJ: Crossing the midline: roles and regulation of Robo receptors. Neuron 28: 767-777, 2000.

7. Garbe DS and Bashaw GJ: Independent functions of Slit-Robo repulsion and Netrin-Frazzled attraction regulate axon crossing at the midline in Drosophila. J Neurosci 27: 3584-3592, 2007.

8. Wang B, Xiao Y, Ding BB, Zhang N, Yuan X, Gui L, Qian KX, Duan S, Chen Z, Rao Y and Geng JG: Induction of tumor angiogenesis by Slit-Robo signaling and inhibition of cancer growth by blocking Robo activity. Cancer Cell 4: 19-29, 2003.

9. Grone J, Doebler O, Loddenkemper C, Hotz B, Buhr HJ and Bhargava S: Robo1/Robo4: differential expression of angiogenic markers in colorectal cancer. Oncol Rep 15: 1437-1443, 2006.

10. Seth P, Lin Y, Hanai J, Shivalingappa V, Duyao MP and Sukhatme VP: Magic roundabout, a tumor endothelial marker: expression and signaling. Biochem Biophys Res Commun 332: 533-541, 2005.

11. Marlow R, Strickland P, Lee JS, Wu X, Pebenito M, Binnewies M, Le EK, Moran A, Macias H, Cardiff RD, Sukumar S and Hinck L: SLITs suppress tumor growth in vivo by silencing Sdf1/Cxcr4 within breast epithelium. Cancer Res 68: 7819-7827, 2008.

12. Avci ME, Konu O and Yagci T: Quantification of SLIT-ROBO transcripts in hepatocellular carcinoma reveals two groups of genes with coordinate expression. BMC Cancer 8: 392, 2008.

13. Narayan G, Goparaju C, Arias-Pulido H, Kaufmann AM, Schneider A, Durst M, Mansukhani M, Pothuri B and Murty VV: Promoter hypermethylation-mediated inactivation of multiple Slit-Robo pathway genes in cervical cancer progression. Mol Cancer 5: 16, 2006.

14. Stella MC, Trusolino L and Comoglio PM: The Slit/Robo system suppresses hepatocyte growth factor-dependent invasion and morphogenesis. Mol Biol Cell 20: 642-657, 2009.

15. Denk AE, Bettstetter M, Wild PJ, Hoek K, Bataille F, Dietmaier W and Bosserhoff AK: Loss of maspin expression contributes to a more invasive potential in malignant melanoma. Pigment Cell Res 20: 112-119, 2007.

16. Bundscherer A, Hafner C, Maisch T, Becker B, Landthaler M and Vogt T: Antiproliferative and proapoptotic effects of rapamycin and celecoxib in malignant melanoma cell lines. Oncol Rep 19: 547-553, 2008.

17. Jacob K, Bosserhoff AK, Wach F, Knuchel R, Klein EC, Hein R and Buettner R: Characterization of selected strongly and weakly invasive sublines of a primary human melanoma cell line and isolation of subtractive cDNA clones. Int J Cancer 60: 668-675, 1995.

18. Wolf K, Wu YI, Liu Y, Geiger J, Tam E, Overall C, Stack MS and Friedl P: Multi-step pericellular proteolysis controls the transition from individual to collective cancer cell invasion. Nat Cell Biol 9: 893-904, 2007.

19. Dickson BJ: Molecular mechanisms of axon guidance. Science 298: 1959-1964, 2002.

20. Xu Y, Li WL, Fu L, Gu F and Ma YJ: Slit2/Robo1 signaling in glioma migration and invasion. Neurosci Bull 26: 474-478, 2010. 
21. Mertsch S, Schmitz N, Jeibmann A, Geng JG, Paulus W and Senner V: Slit2 involvement in glioma cell migration is mediated by Robo1 receptor. J Neurooncol 87: 1-7, 2008.

22. Small EM, Sutherland LB, Rajagopalan KN, Wang S and Olson EN: MicroRNA-218 regulates vascular patterning by modulation of Slit-Robo signaling. Circ Res 107: 1336-1344, 2010.

23. Mueller DW, Rehli M and Bosserhoff AK: miRNA expression profiling in melanocytes and melanoma cell lines reveals miRNAs associated with formation and progression of malignant melanoma. J Invest Dermatol 129: 1740-1751, 2009.

24. Denk AE, Kaufmann S, Stark K, Schedel J, Lowin T, Schubert T and Bosserhoff AK: Slit3 inhibits Robo3-induced invasion of synovial fibroblasts in rheumatoid arthritis. Arthritis Res Ther 12: R45, 2010.

25. Payne AS and Cornelius LA: The role of chemokines in melanoma tumor growth and metastasis. J Invest Dermatol 118: 915-922, 2002.

26. Yiin JJ, Hu B, Jarzynka MJ, Feng H, Liu KW, Wu JY, Ma HI and Cheng SY: Slit2 inhibits glioma cell invasion in the brain by suppression of Cdc42 activity. Neuro Oncol 11: 779-789, 2009.

27. Zheng D, Liu BB, Liu YK, Kang XN, Sun L, Guo K, Sun RX, Chen J and Zhao Y: Analysis of the expression of Slit/Robo genes and the methylation status of their promoters in the hepatocellular carcinoma cell lines. Zhonghua Gan Zang Bing Za Zhi 17: 198-202, 2009 (In Chinese).
28. Prasad A, Paruchuri V, Preet A, Latif F and Ganju RK: Slit-2 induces a tumor-suppressive effect by regulating beta-catenin in breast cancer cells. J Biol Chem 283: 26624-26633, 2008.

29. Yuasa-Kawada J, Kinoshita-Kawada M, Rao Y and Wu JY: Deubiquitinating enzyme USP33/VDU1 is required for Slit signaling in inhibiting breast cancer cell migration. Proc Natl Acad Sci USA 106: 14530-14535, 2009.

30. Rhee J, Buchan T, Zukerberg L, Lilien J and Balsamo J: Cables links Robo-bound Abl kinase to N-cadherin-bound beta-catenin to mediate Slit-induced modulation of adhesion and transcription. Nat Cell Biol 9: 883-892, 2007.

31. Spangler B, Vardimon L, Bosserhoff AK and Kuphal S: Posttranscriptional regulation controlled by E-cadherin is important for c-Jun activity in melanoma. Pigment Cell Melanoma Res 24: 148-164, 2011.

32. Knirsh R, Ben Dror I, Spangler B, Matthews GD, Kuphal S, Bosserhoff AK and Vardimon L: Loss of E-cadherin-mediated cell-cell contacts activates a novel mechanism for up-regulation of the proto-oncogene c-Jun. Mol Biol Cell 20: 2121-2129, 2009.

33. Wong K, Ren XR, Huang YZ, Xie Y, Liu G, Saito H, Tang H, Wen L, Brady-Kalnay SM, Mei L, Wu JY, Xiong WC and Rao Y: Signal transduction in neuronal migration: roles of GTPase activating proteins and the small GTPase Cdc42 in the Slit-Robo pathway. Cell 107: 209-221, 2001. 